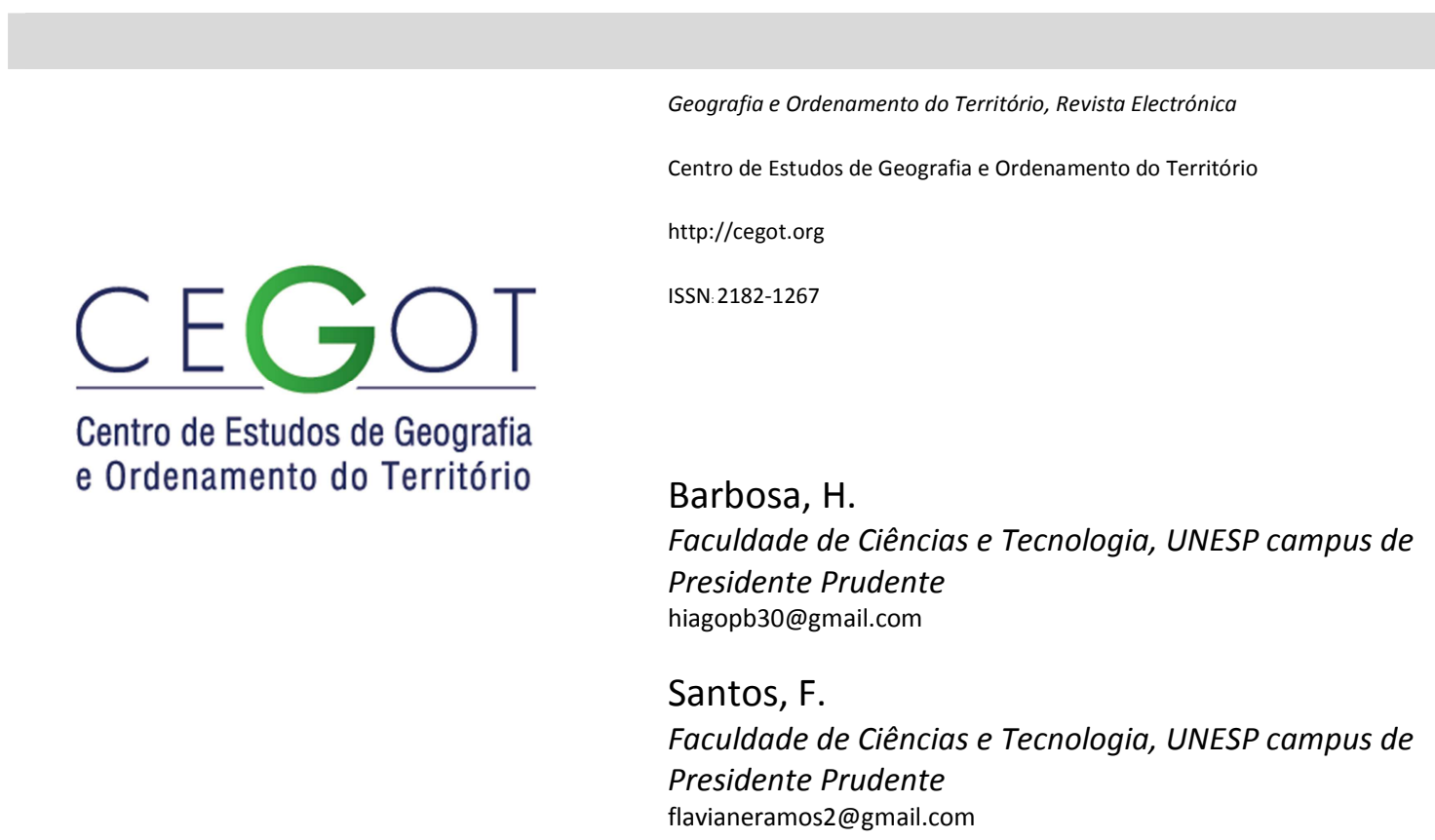

\title{
Episódio de onda de frio em cidade de clima tropical: estudo de caso de Presidente Prudente, São Paulo (Brasil)
}

Referência: Barbosa, H. e Santos, F. (2014). Episódio de onda de frio em cidade de clima tropical: estudo de caso de Presidente Prudente, São Paulo (Brasil). Revista de Geografia e Ordenamento do Território (GOT), n.o 6 (dezembro). Centro de Estudos de Geografia e Ordenamento do Território, p. 23-43

\section{Resumo}

Presidente Prudente localiza-se no oeste do Estado de São Paulo (Sudeste do Brasil), região de confronto entre os sistemas atmosféricos tropicais e extratropicais. A cidade é conhecida como uma das mais quentes do Estado de São Paulo, devido ao registro de altas temperaturas em boa parte do ano. O objetivo do presente artigo foi o de analisar um episódio de onda de frio, que ocorreu entre os dias 12 a 18 de julho do ano de 2000 e trouxe diversas consequências para a população prudentina, ou seja, esses dias com temperaturas baixas propiciaram impactos na agricultura, no comércio e na saúde das pessoas.

Palavras-Chave: Onda de frio, clima tropical, ordenamento do território, Presidente Prudente.

\begin{abstract}
Presidente Prudente is located in the west of São Paulo State (southeastern Brazil), region of confrontation between the tropical and extratropical weather systems. The city is known as one of the hottest of the São Paulo State, due to record high temperatures in much of the year. The aim of this paper was to analyze an episode of cold wave who took place between
\end{abstract}


12-18 July in the year 2000 and brought many consequences for prudentina population, in other words, those days with low temperatures propitiated impacts on agriculture, commerce and people's health.

Keywords: cold wave, tropical climate, territorial planning, Presidente Prudente;

\section{Introdução}

A análise dos processos climáticos em escala regional representa uma ferramenta de fundamental importância para a compreensão da dinâmica climática e da natureza dos eventos climáticos extremos ao redor do globo, e também na escala local através de estudos dos espaços urbano e rural, por meio de uma perspectiva de análise pautada na climatologia.

Dessa forma, o presente trabalho, por meio de uma abordagem sistêmica de tais processos, apresentará ao leitor um quadro detalhado e coerente justamente sobre mais um dentre tantos eventos extremos oriundos da dinâmica climática: a onda de frio ocorrida na cidade de Presidente Prudente entre os dias 12 e 18 de julho, do ano 2000. Para atingirmos tal objetivo, torna-se necessário dividir este trabalho em partes que se completam.

Num primeiro momento, foi realizada uma breve caracterização da área de estudo: a cidade de Presidente Prudente, localizada no oeste paulista. Obviamente que localizar e caracterizar a área de estudo é de suma importância para atingirmos um resultando final satisfatório, afinal, para compreender a dinâmica climática que estabelece os tipos de tempo (e ocasiona os eventos extremos) na cidade de Presidente Prudente, é de extrema importância identificar a quais processos climáticos a cidade está submetida.

Em seguida foi realizado, o que denominandos da essência deste estudo. A partir dos dados meteorológicos fornecidos, realizamos - embasados na fundamental contribuição de Carlos Augusto de Figueiredo Monteiro (1971 e 1976) - a análise rítmica e a identificação dos tipos de tempo atuantes durante o período considerado (12 a 18 de julho de 2000) na cidade de Presidente Prudente.

Num terceiro momento, foi realizada a caracterização do fenômeno em si, ou seja, demonstraremos ao leitor, a partir da verificação e estudo dos dados fornecidos, o que seria uma onda de frio, o quê caracteriza a sua existência na área de estudo considerada e a 
relação dessa com a saúde dos citadinos. Posteriormente, apresentaremos algumas considerações sobre o conforto térmico enquanto elemento fundamental para a qualidade de vida no espaço intraurbano de Presidente Prudente e, ao mesmo tempo, algumas mitigações - que têm por objetivo minimizar os efeitos adversos das ondas de frios - serão apresentadas ao leitor.

Por fim, fizemos algumas considerações finais sobre tudo que apresentamos ao longo das diversas páginas que compõem este trabalho, procurando, por meio de algumas constatações, salientar a importância de trabalharmos os eventos extremos em Presidente Prudente a partir de uma analise climática voltada para o espaço urbano em questão, utilizando as contribuições de Monteiro encontrados na Teoria e Clima Urbano (1976).

\subsection{Caracterização de Presidente Prudente (São Paulo)}

O município de Presidente Prudente (figura 1) está situado no oeste do Estado de São Paulo no Brasil, compreendido em coordenadas geográficas entre a latitude $22^{\circ} 07^{\prime} \mathrm{S}$ e a longitude $51^{\circ} 23^{\prime} \mathrm{W}$. De acordo com o Censo Demográfico do IBGE (Instituto Brasileiro de Geografia e Estatistíca) de 2010, a população é de aproximadamente 208 mil habitantes. O munícipio foi criado em 1917 e apresentou ao longo do tempo diferentes tipos de formação a partir da cultura predominante da época (café, algodão, pecuária etc.). Situa-se cerca de 600 quilômetros do oceano, com uma altitude variando de 390 a 490 metros sobre o nível do mar.

A cidade situa-se numa área de transição entre os climas zonais controlados pelos sistemas tropicais, que lhe confere elevadas temperaturas de primavera e verão, e pelos sistemas extratropicais (massas polares) que ocasionam episódios de invasão das frentes frias e do ar polar no outono e inverno, provocando baixas temperaturas. (Sant'anna Neto e Tomamaselli, 2009).

Além disso, está sob o regime de um clima tropical, alternadamente seco e chuvoso. Em escala zonal, têm seu clima controlado pelos sistemas tropicais, ou seja, ação predominante das massas Tropical Atlântica (Ta), Tropical Continental (Tc) e Equatorial Continental (Ec), conforme figura 2, principalmente no período de primavera e verão, que são responsáveis pelas elevadas temperaturas desta época do ano. E pelos sistemas extratropicais (massas 
polares), isto é, a penetração dos sistemas frontais (Frente Polar Atlântica) e a atuação da massa Polar Atlântica (Pa), que são responsáveis pelo aumento da velocidade do vento, pela queda brusca da temperatura e longos períodos de estiagens (Sant'anna neto e Tomamaselli, 2009).

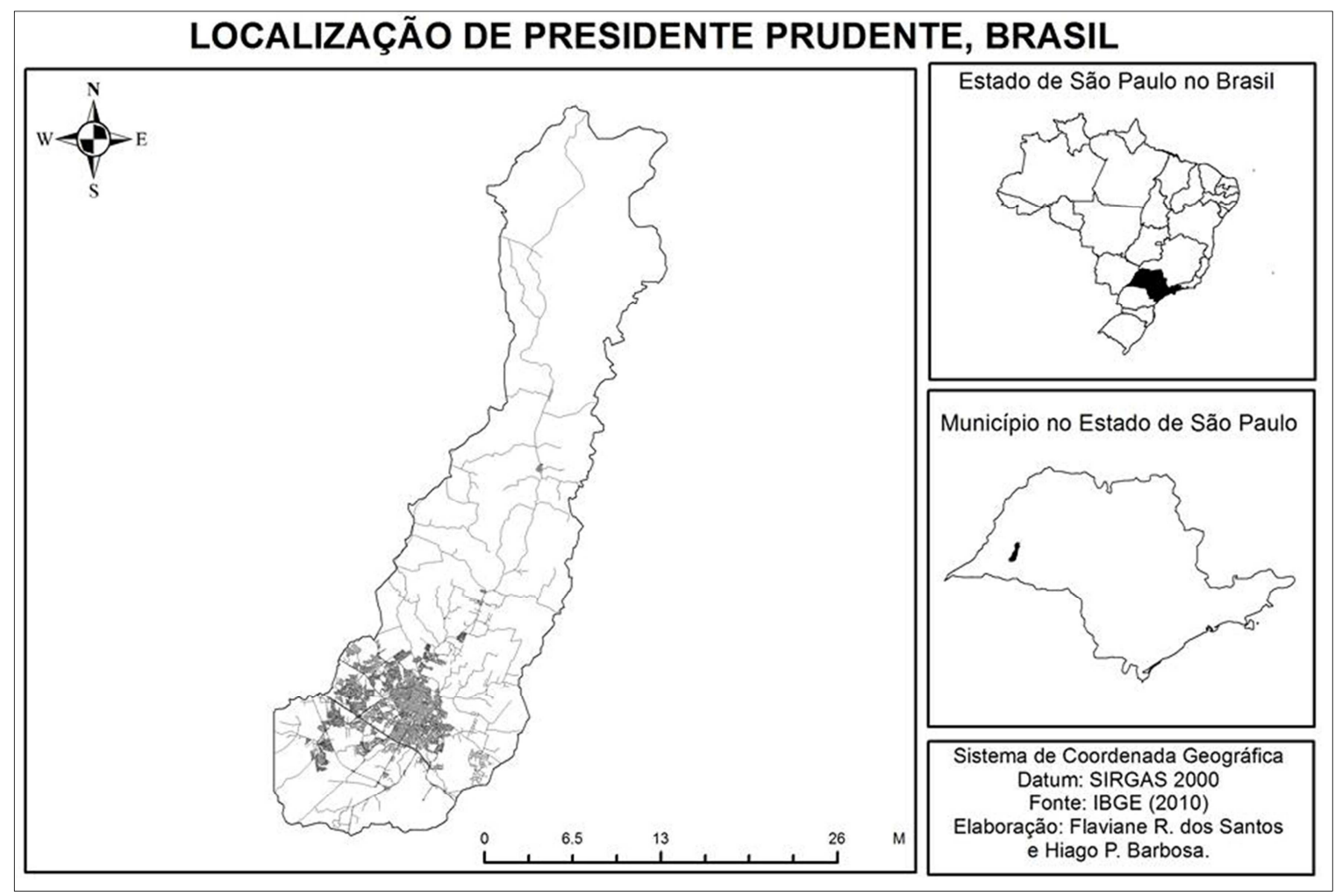

Figura 1 - Localização de Presidente Prudente no Estado de São Paulo e no Brasil.

Na maior parte do ano a cidade de Presidente Prudente está sob a ação do sistema tropical atlântico (massa de ar quente, estável e pouco úmida), proporcionando elevadas temperaturas.

Por meio de uma análise temporal dos dados de temperatura do ar registrados na Estação Meteorológica da Faculdade de Ciências e Tecnologia da UNESP (Universidade Estadual Paulista), se tornou possível a realização de uma discussão mais ampla do assunto. Analisando a série histórica de 1961 a 2010, verificou-se que a temperatura média da máxima foi de $29,1^{\circ} \mathrm{C}$, enquanto a temperatura média da mínima foi de $18^{\circ} \mathrm{C}$. 


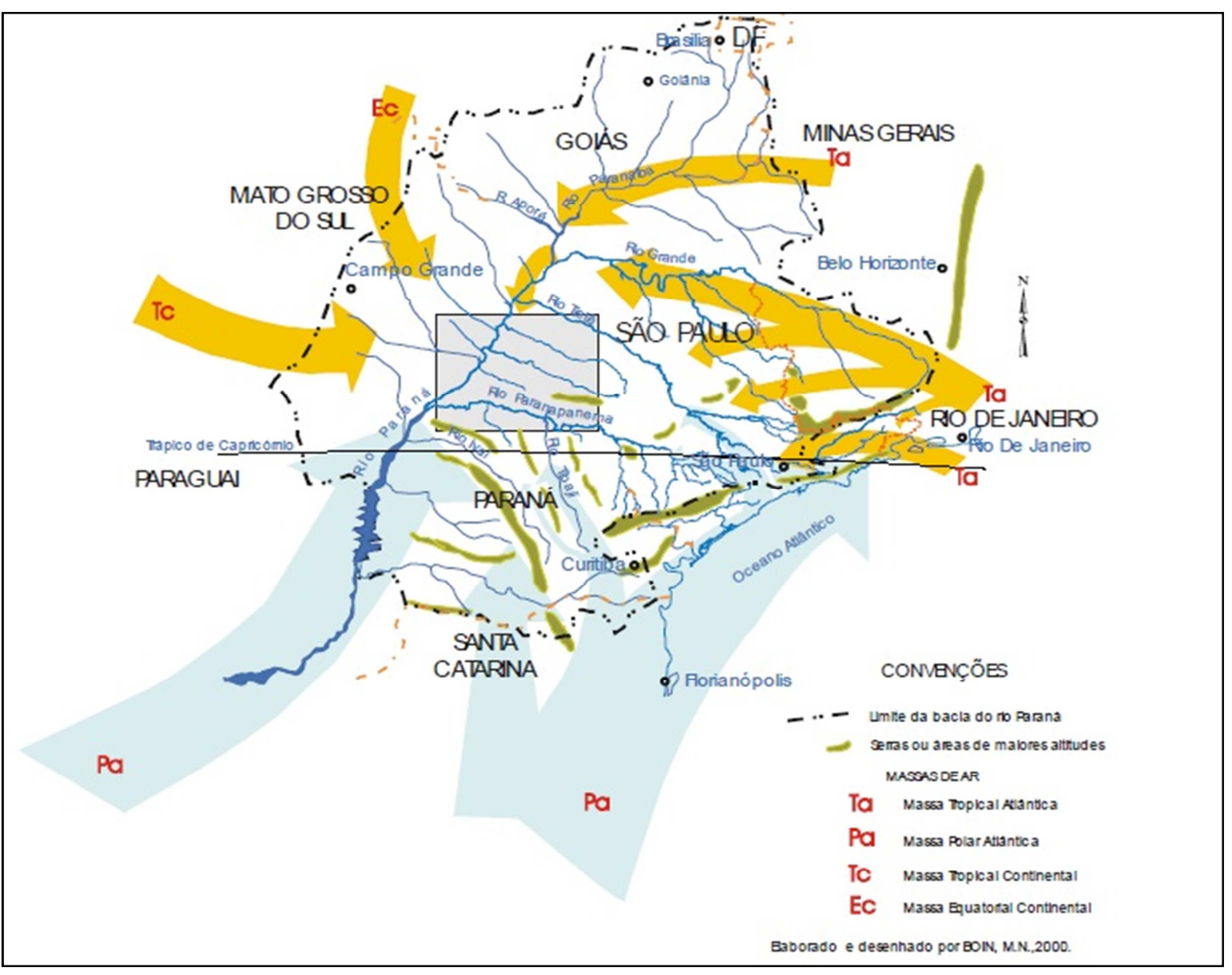

Figura 2 - Trajetos preferenciais das massas de ar que atingem o Oeste Paulista Fonte: Boin (2000).

O ano de 2002 destacou-se como o de temperatura média das máximas (figura 3) de maior valor, ou seja, está dentro dos anos mais quentes registrados, apresentando a temperatura de $30,6^{\circ} \mathrm{C}$. Seguido pelo ano de 2007 , que apresentou uma temperatura média das máximas de $30,4^{\circ} \mathrm{C}$.

O recorde entre os anos com temperaturas mais baixas (figura 4), foi alcançado no ano de 1962 com temperatura média das mínimas registrando $14,9^{\circ} \mathrm{C}$. Outros anos com temperaturas mais baixas, que se destacaram foram o de 1963 e 1968 (respectivamente com a mesma temperatura de $15,1^{\circ} \mathrm{C}$ ) e o ano de 1966 que apresentou uma temperatura de $15,7^{\circ} \mathrm{C}$. Sabe-se que a utilização dos valores médios não são os mais adequados para tratar a questão de um episódio de onda de frio, por isso, foram realizadas análises diárias (com valores absolutos de mínima, média e máxima térmica) durante o período estudado nesse trabalho. 
Observa-se nas figuras 3 e 4 as temperaturas médias das máximas e mínimas, uma tendência crescente nos valores de temperatura média das máximas e também uma tendência crescente mais acentuada na temperatura média das mínimas. Esse fenômeno de aumento nas temperaturas pode ser explicado pelo processo de expansão da malha urbana, que cresceu sem levar em consideração o contexto climático e ambiental da cidade, bem como a falta de efetivação de ações de planejamento.

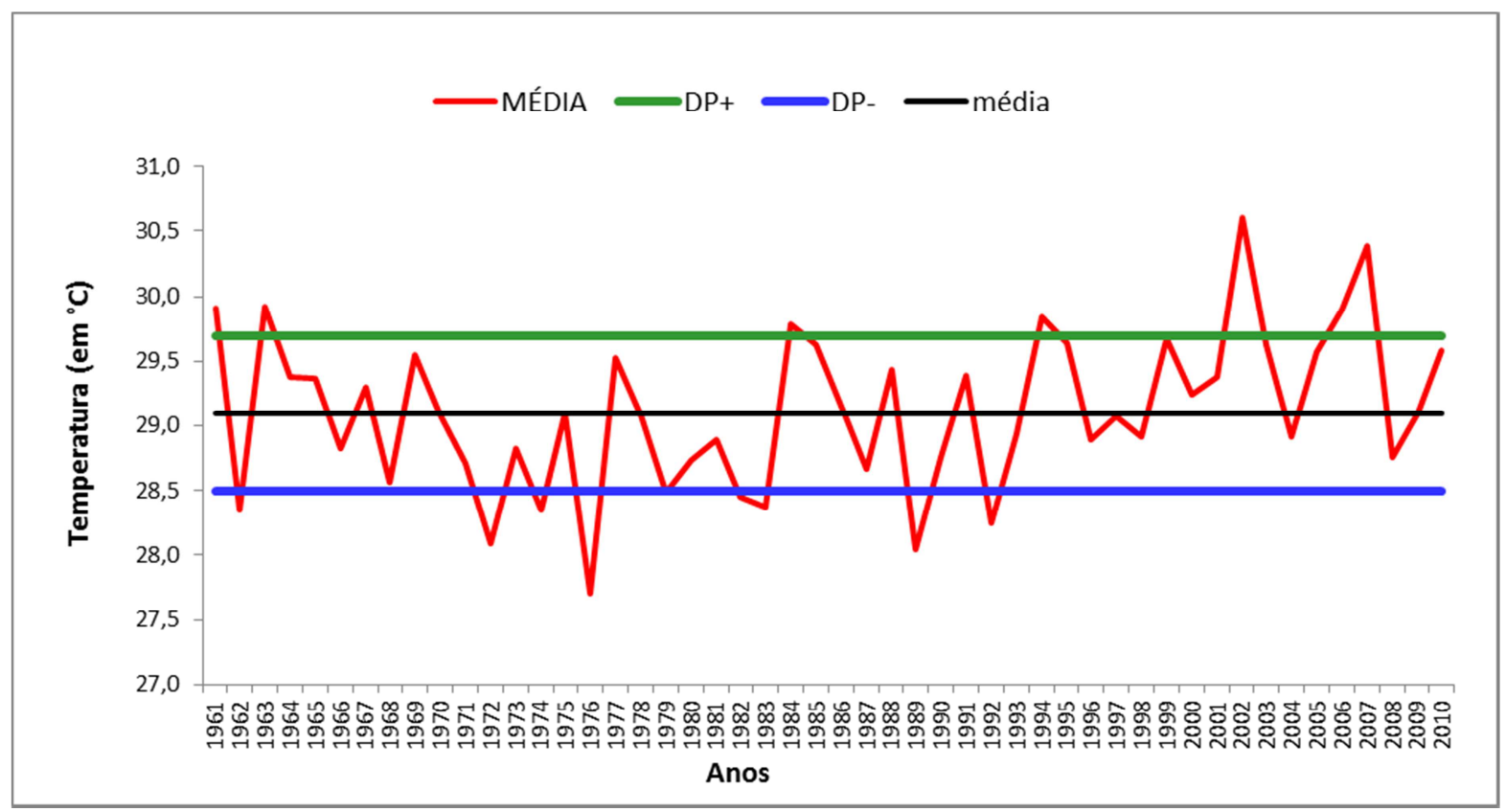

Figura 3 - Variabilidade das temperaturas médias das máximas de 1961 a 2010 na cidade de Presidente Prudente (São Paulo, Brasil) Fonte: Dados da Estação Meteorológica FCT/UNESP

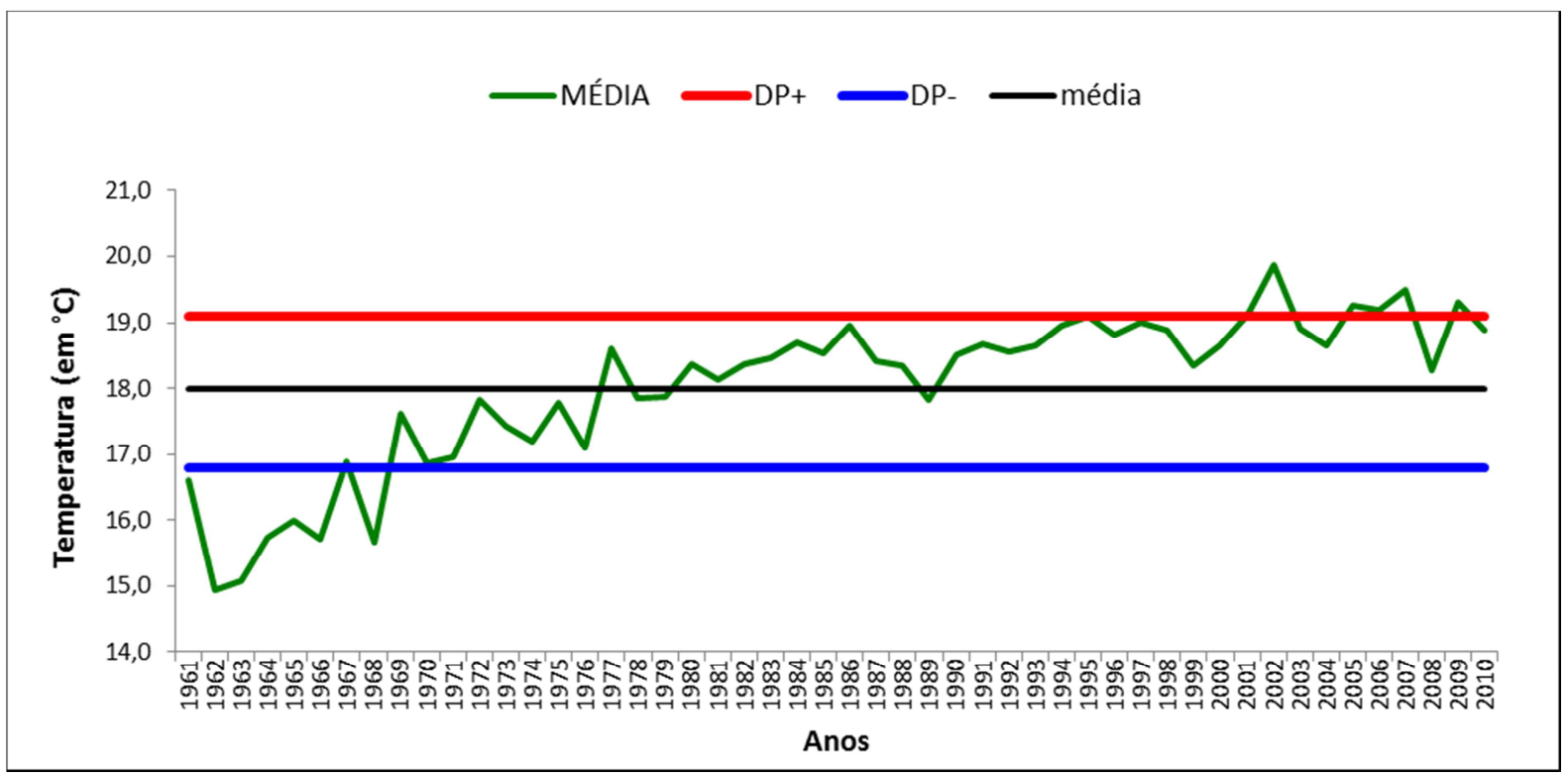

Figura 4 - Variabilidade das temperaturas médias das mínimas de 1961 a 2010 na cidade de Presidente Prudente (São Paulo, Brasil) Fonte: Dados da Estação Meteorológica FCT/UNESP 
Não é difícil perceber que os anos que obtiveram as médias de temperatura mínima mais baixa pertencem justamente à década de 1960, período em que o processo de urbanização prudentina pouco havia se iniciado. Em consequência, os anos que apresentaram essas médias mínimas de temperatura mais elevadas, dizem respeito à década de 2000 , onde a cidade se encontrava em um estágio de urbanização muito mais consolidado.

Em regiões tropicais como a que se encontra Presidente Prudente, pode-se considerar a existência de apenas duas estações bem definidas: uma chuvosa (de outubro a março), que concentra cerca de $70 \%$ do volume pluviométrico anual e, outra, mais seca (de abril a setembro), quando chove apenas 30\% do total (Ibidem, 2009).

De acordo com Souza (2004), em Presidente Prudente, o episódio extremo de maior repercussão local é a chuva, tanto pelo seu excesso quanto pela ausência. As rajadas de ventos, diminuição da umidade relativa do ar e as ondas de calor e frio podem também ocasionar forte repercussão no espaço geográfico, como pode ser observado no decorrer do presente trabalho, que discorre sobre os impactos de uma onda de frio que atingiu a população prudentina no mês de Julho de 2000.

\section{Metodologia}

Para a investigação das ondas de frio é necessário uma adoção da metodologia utilizada pela Organização Meteorológica Mundial (OMM), segundo a qual para a existência de uma onda de frio é necessário que se registrem valores diários de temperatura mínima inferiores à média diária do período de referência durante, pelo menos, seis dias consecutivos (Monteiro, 2013). O período de referência nesse trabalho se trata do mês de julho de 2000 em Presidente Prudente.

Em contrapartida, por se tratar de uma cidade localizada no hemisfério sul e, portanto de clima tropical, uma onda de frio é caracterizada por um período com mais de três dias consecutivos com valores de temperatura mínima abaixo dos $10^{\circ} \mathrm{C}$ (este critério foi adotado pelos autores, sobretudo para uma caracterização de onda de frio na cidade de Presidente Prudente que apresenta um clima do tipo tropical), distinguindo-se dos parâmetros de cidades do hemisfério norte, sobretudo as que possuem clima temperado. 
Para a realização deste trabalho foram utilizados os dados meterológicos da Estação Meteorológica da Faculdade de Ciências e Tecnologia da UNESP localizada na cidade de Presidente Prudente.

É importante ressaltar, que os dados meteorológicos utilizados para a elaboração da análise rítmica foram os registrados às $9 \mathrm{~h}$ (12h GMT), bem como a identificação dos sistemas atmosféricos atuantes no período.

Os sistemas atmosféricos atuantes na região durante o período analisado foram identificados por meio das imagens de satélite GOES e das cartas sinóticas de superfície da Marinha do Brasil, conjuntamente com os dados meteorológicos de superfície.

O aporte teórico-metodológico utilizado para a realização desse trabalho está pautado no S.C.U. (Sistema Clima Urbano) elaborado por Monteiro (1976), como também na análise rítmica dos tipos de tempo elaborada pelo mesmo autor e publicada no ano de 1971.

A análise dos dados para a elaboração da análise rítmica foi pautada na proposta de Monteiro (1971) com o conceito de ritmo climático, que considera a sucessão dos tempos atmosféricos em escala diária.

De acordo com Monteiro (1971) a ideia de ritmo é concebida através da representação concomitantemente dos elementos fundamentais do clima em unidade de tempo cronológica pelo menos diárias, compatíveis com a representação da circulação atmosférica regional, geradora dos estados atmosféricos que se sucedem e constituem o fundamento de ritmo.

Sendo a análise rítmica uma abordagem essencialmente dinâmica, torna-se necessário um perfeito entrosamento entre as observações locais detalhadas em unidades de tempo cronológico adequadas como também os elementos de análise espacial da circulação atmosférica. (Monteiro, 1971, p. 13).

Neste mesmo trabalho, o autor ressalta a importância da utilização do ritmo climático em estudos em diferentes áreas da climatologia. O ritmo climático relacionado aos problemas urbanos é entendido por Monteiro (1971) como a terceira ordem de preocupação do programa, afirmando que a abordagem setorial da cidade, ligará o ritmo de sucessão do tempo com problemas de maior significação na organização do espaço urbano. 
As notícias de jornais são uma importante ferramenta para a análise dos episódios extremos que ocorrem nos espaços rural e urbano, sobretudo aqueles que trazem maiores impactos para a sociedade.

Dessa forma, utilizamos como fonte de consulta dois importantes jornais na cidade de Presidente Prudente, "O imparcial" e o "Oeste Notícias". Por meio dessas fontes foi possível o recolhimento de algumas reportagens que trataram sobre o evento climático que antigiu os habitantes de Presidente Prudente, sobretudo as consequências geradas no campo, na cidade e a influência no comércio.

\section{Resultados}

\subsection{Análise rítmica: as variavéis meteorológicas e os tipos de tempo}

Monteiro (1971) divulgou sua proposta de "análise rítmica" como uma forma de procedimento, no escopo da Climatologia Geográfica, de explicar a gênese, a dinâmica e o impacto dos elementos meteorológicos e suas repercussões no espaço geográfico.

A análise rítmica (figura 5) consiste na construção de um gráfico, em escala diária, dos principais elementos meteorológicos responsáveis pela constituição dos "tipos de tempo" (massas de ar e sistemas frontais, considerados na análise feita pela climatologia). Com base na análise das combinações destes elementos (pressão atmosférica, temperatura, precipitação, umidade relativa, direção e velocidade do vento, nebulosidade e fases da lua para áreas costeiras) e da interpretação das cartas sinóticas de superfície e das imagens de satélite, são reconhecidos e identificados os sistemas atmosféricos da baixa troposfera (circulação secundária).

É a partir dessa análise que se torna possível estabelecer uma comparação entre diferentes períodos, sendo assim possível identificar os episódios de eventos extremos em geral (estiagem, ondas de frio, ondas de calor, vendavais, enchentes etc), ou seja, identificando os acontecimentos excepcionais que repercutem no espaço geográfico. De acordo com Souza (2005) pode-se recompor o encadeamento dos tipos de tempo que ocorreram num determinado período (episódio) e associar um acontecimento adverso (ou extremo) com a gênese do clima e a dinâmica atmosférica. Sendo esse tipo de representação gráfica 
fundamental na análise geográfica do clima. Em outros termos, sem a compreensão dos ritmos climáticos não há possibilidades reais de se planejar adequadamente os diversos tipos de uso do solo e ocupações humanas em áreas das mais heterogêneas possíveis, sendo essa de enorme valia para os estudos de meio ambiente, para a agricultura, o planejamento urbano, entre outros.

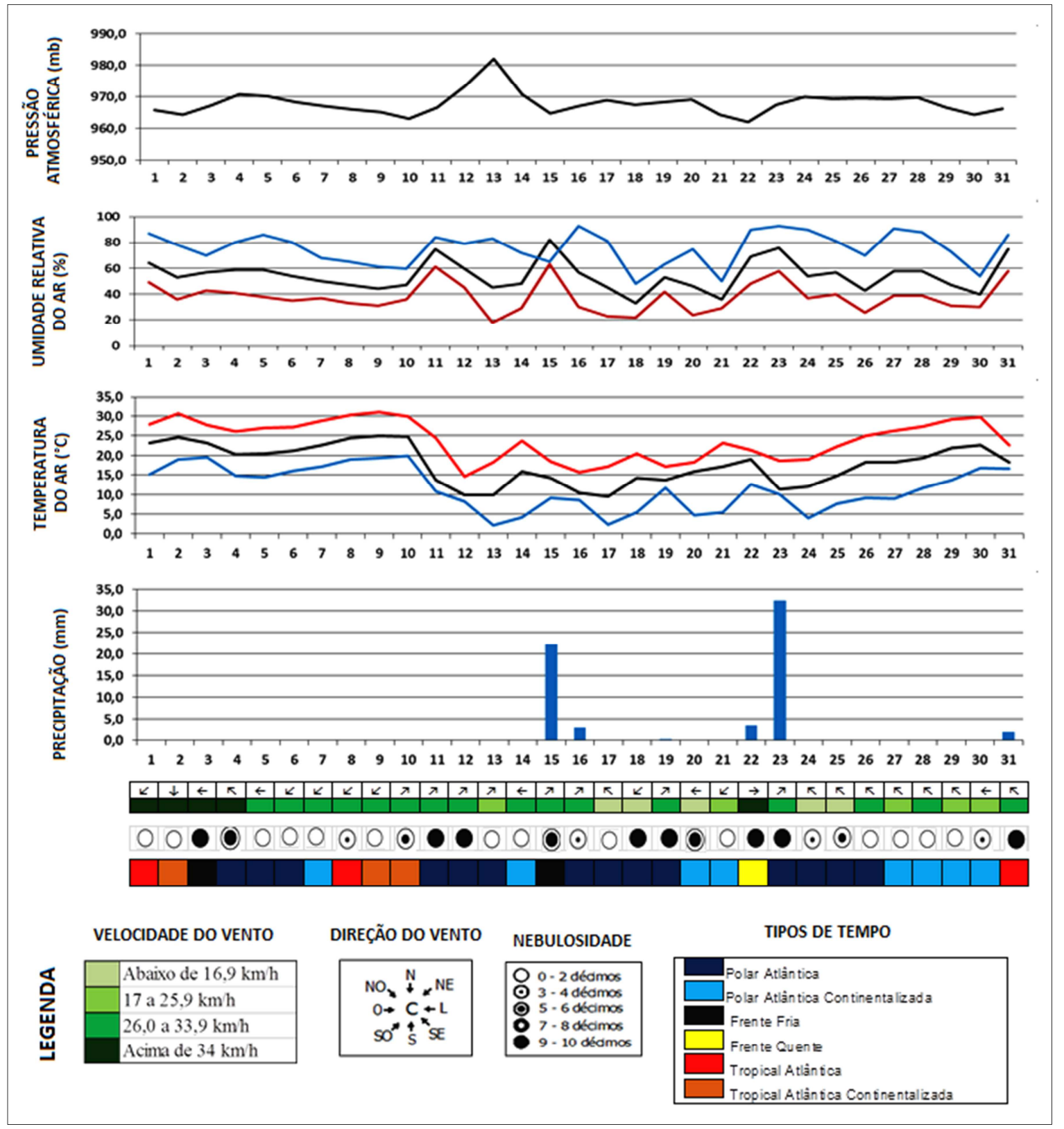

Figura 5 - Análise Rítmica do mês de julho de 2000

Fonte: Dados da Estação Meteorológica FCT/UNESP 
É necessário explicar que no ano de 2000 a América do Sul esteve sob a atuação da La Niña, e em diversas cidades de diferentes países da porção sul da América do Sul ocorreram episódios de onda de frio.

As memoráveis ondas de frio de 1955, 1957, 1965, 1975, 1984, 1988, 1991, 1994, 1996, 1999, 2000 e 2004 tiveram lugar sob La Niña ou com a costa da América do Sul no Pacífico apresentando anomalias negativas de temperatura. Significa, segundo Eugenio Hackbart, que historicamente os mais importantes episódios de frio da última metade de século tiveram lugar sob condições de Pacífico resfriado. (Guiar, 2007, p.1).

De acordo com Firpo, Sansigolo e Assis (2012) a ocorrência da La Niña começou no ano de julho de 2000 e teve seu término em fevereiro de 2001, com duração de oito meses. É nesse sentido, que podemos explicar a entrada do ar polar vindo do Pacífico, ocasionando assim, o fortalecimento das massas de ar polar vindas dessa região. De fato, com situações atmosféricas como essa, estados localizados ao norte do Brasil (Amazonas, Rondônia, Acre) e ao Centro-Oeste (Mato Grosso e Mato Grosso do Sul) sofrem forte influência nas condições meteorológicas, apresentando temperaturas mais amenas e baixas para essas regiões.

No período de 01 a 31 de julho, os tipos de tempo que atuaram na região foram controlados pelos sistemas extratropicais (Polar Atlântica e Polar Atlântica Tropicalizada), sistemas tropicais (Tropical Atlântica e Tropical Atlântica Continentalizada) e sistemas frontais (frente fria e frente quente) com menor intensidade.

$\mathrm{Na}$ análise feita neste trabalho do mês de julho de 2000 , se fez presente na maior parte dos dias os sistemas extratropicais (Polar Atlântica e Polar Atlântica Tropicalizada).

Quando a massa Polar Atlântica chega à região do oeste paulista, esta causa à diminuição das temperaturas e grande amplitude térmica diária, sendo esse sistema estável, que apresenta pouca umidade e elevada pressão atmosférica, dando origem aos dias de tipos de tempo com temperaturas mais amenas e valores de umidade do ar mais baixos. Quando a pressão atmosférica começa a diminuir gradativamente e a temperatura se eleva, se inicia a atuação da Polar Atlântica Tropicalizada.

Como afirma Amorim (2000) as penetrações do sistema polar Atlântico são mais intensas sobre a região de Presidente Prudente, antecedida de passagens de frente polar e a posição 
latitudinal da área estudada faz com que o sistema polar sofra tropicalização acentuada, mesmo nessa época do ano (inverno).

Com menor intensidade, cerca de cinco dias estiveram presentes os sistemas tropicais (Tropical Atlântica e Tropical Atlântica Continentalizada), onde com atuação desses houve aumento de temperatura, diminuição da pressão atmosférica, ausência de precipitações e diminuição da umidade, se intensificando com a atuação da massa Tropical Atlântica Continentalizada. Como afirma Sant'Anna Neto e Tommaselli (2009) esses sistemas se originam no anticiclone marítimo e atuam o tempo todo de modo constante, sobre o oeste paulista, trazendo estabilidade no tempo nos meses de outono e inverno, em decorrência da subsidência do ar superior.

Já os sistemas frontais estiveram presentes em três dias do mês de julho, sendo estes resultados do encontro de dois sistemas antagônicos (tropicais e polares) que geram instabilidade atmosférica em área de descontinuidades das massas de ar, com características de aumento de nebulosidade, queda de precipitação e diminuição da temperatura. Vale ressaltar que são na atuação desses sistemas que foram observados os maiores índices de precipitação e velocidade do vento acima de $26 \mathrm{~km} / \mathrm{h}$.

Como se pode observar na análise rítmica do mês em questão, após a passagem dos sistemas frontais, as massas polares tiveram duração de aproximadamente de quatro dias, exceto o sistema que chegou depois do dia 15 e do dia 23 que tiveram permanência maior na região. A maioria dos anticiclones migratórios, ao ingressarem no país, desloca-se para o oceano, não trazendo precipitações para a cidade de Presidente Prudente, explicando assim o fato de baixos valores de precipitação registrados no período.

\subsection{Onda de frio e sua repercussão no espaço geográfico prudentino}

Conforme já exposto anteriormente, as ondas de frio são fenômenos climáticos que consistem na permanência de baixas temperaturas em uma determinada área durante um determinado período de tempo. Contudo, para representarem um evento extremo propriamente dito, as ondas de frio devem ocorrer em uma região onde o clima seja caracterizado, predominantemente, por temperaturas elevadas durante a maior parte do ano, como é o caso da cidade de Presidente Prudente. 
Em Presidente Prudente, as quedas bruscas na temperatura são ocasionadas pela entrada de sistemas polares, principalmente a massa Polar Atlântica que se origina no anticiclone migratório polar, mais especificamente, na latitude do mar de Weddel, próximo a Antártida. Dessa forma, os ventos do quadrante sul (S, SW e SE) atingem o oeste paulista ocasionando baixas temperaturas e elevada pressão atmosférica, formando tipos de tempo estáveis e ocasionado, em alguns casos, ondas de frio.

O mês de julho do ano 2000, em Presidente Prudente, foi marcado pela ocorrência de uma onda de frio que começou no dia 12 daquele mês e estendeu-se até o dia 18 . No período em questão, os sistemas polares atuaram de maneira enfática, com o avanço da massa Polar Atlântica. Não por acaso, nos sete dias compreendidos entre 12 e 18 de julho, registraramse as duas menores temperaturas mínimas e médias do mês: no dia 13, os termômetros marcaram apenas $2,2^{\circ} \mathrm{Ce}$, quatro dias depois, $2,3^{\circ} \mathrm{C}$.

No quadro 1 podemos verificar os valores absolutos máximos e mínimos dos dias analisados, bem como a média diária da temperatura.

\begin{tabular}{|c|c|c|c|}
\hline \multirow{2}{*}{ DATA } & $\begin{array}{c}\text { TEMPERATURA } \\
\text { MíNIMA (Tmin) }\end{array}$ & $\begin{array}{c}\text { TEMPERATURA } \\
\text { MÁXIMA (TMAX) }\end{array}$ & MÉDIA DIÁRIA \\
\hline $12 / 07 / 2000$ & $8,2^{\circ} \mathrm{C}$ & $14,6^{\circ} \mathrm{C}$ & $9,8^{\circ} \mathrm{C}$ \\
\hline $13 / 07 / 2000$ & $2,2^{\circ} \mathrm{C}$ & $18,2^{\circ} \mathrm{C}$ & $9,9^{\circ} \mathrm{C}$ \\
\hline $14 / 07 / 2000$ & $4,2^{\circ} \mathrm{C}$ & $23,8^{\circ} \mathrm{C}$ & $15,9^{\circ} \mathrm{C}$ \\
\hline $15 / 07 / 2000$ & $9,2^{\circ} \mathrm{C}$ & $18,4^{\circ} \mathrm{C}$ & $14,3^{\circ} \mathrm{C}$ \\
\hline $16 / 07 / 2000$ & $8,6^{\circ} \mathrm{C}$ & $15,6^{\circ} \mathrm{C}$ & $10,4^{\circ} \mathrm{C}$ \\
\hline $17 / 07 / 2000$ & $2,3^{\circ} \mathrm{C}$ & $17,1^{\circ} \mathrm{C}$ & $9,5^{\circ} \mathrm{C}$ \\
\hline $18 / 07 / 2000$ & $5,4^{\circ} \mathrm{C}$ & $20,4^{\circ} \mathrm{C}$ & $14,2^{\circ} \mathrm{C}$ \\
\hline
\end{tabular}

Quadro 1 - Valores térmicos entre os dias 12 a 18 de julho de 2000 em Presidente Prudente Fonte: Dados da Estação Meteorológica FCT/UNESP

As temperaturas máximas nos dias 13 e 17 de julho também foram baixas para os padrões da cidade: no dia 13 a máxima chegou aos $18,2^{\circ} \mathrm{C}$ e no dia 17 os termômetros marcaram $17,1^{\circ} \mathrm{C}$, consequentemente, a média nesses dias foram as mais baixas do mês: respectivamente $9,8^{\circ} \mathrm{C}$ (dia 13 ) e $9,5^{\circ} \mathrm{C}$ (dia 17$)$.

Obviamente que, além da atuação dos sistemas polares e das baixas temperaturas mínimas e médias, outro fator que contribuiu para caracterizar os oito dias em questão como um evento extremo de onda de frio foram as baixas temperaturas máximas: do dia 12 ao dia 17 de julho, a maior temperatura média diária registrada foi $15,9^{\circ} \mathrm{C}$ no dia 14 . 
Considerando a média das temperaturas mínimas registradas no período, temos o valor $5,7^{\circ} \mathrm{C}$, onde a maior temperatura registrada foi justamente no dia $15\left(9,2^{\circ} \mathrm{C}\right)$ e a menor, conforme demonstramos, foi registrada no dia $13\left(2,2^{\circ} \mathrm{C}\right)$. A média das temperaturas máximas foi de $18,3^{\circ} \mathrm{C}$; e o valor máximo registrado foi de $23,8^{\circ} \mathrm{C}$, no dia 14 , enquanto que o valor mínimo foi de $14,6^{\circ} \mathrm{C}$ no dia 12 , início do episódio de onda de frio.

Portanto, por meio de um olhar sistêmico (processos climáticos em escala regional juntamente com os fatores de escala local) e através da verificação empírica dos dados resultantes da dinâmica climática, os dias compreendidos entre 12 e 18 de julho representam, sem qualquer sombra de dúvida, um período de onda de frio na cidade.

Durante os oito dias considerados, a imprensa local divulgou diversas notícias referentes às consequências da onda de frio. No dia 14, por exemplo, o jornal "O Imparcial" apresentou a matéria "Meteorologia registra a temperatura mais baixa" (figura 6), constatando que o dia anterior (13 de julho) tinha sido o dia mais frio do ano até aquele momento. Como sabemos os dias 13 e 17 daquele mês foram, de fato, os dias mais frios de 2000.

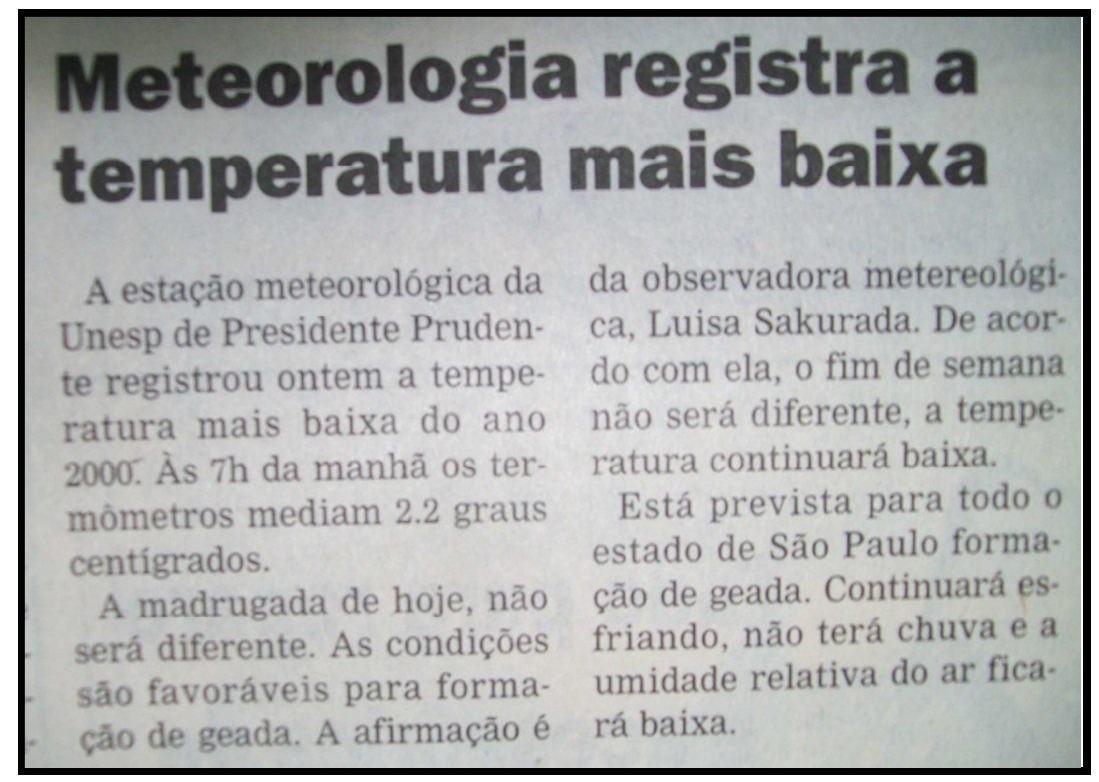

Figura 6 - Notícia publicada pelo "Jornal O Imparcial" Fonte: Jornal O Imparcial (julho de 2000).

Outras notícias como a perda da produção agrícola em algumas regiões do município (figura 6), e a consequente elevação dos preços desses produtos (figuras 7 e 8) e o aumento na venda de agasalhos devido às baixas temperaturas (figura 9) permearam as páginas dos jornais locais entre os dias 10 e 19 de julho. 


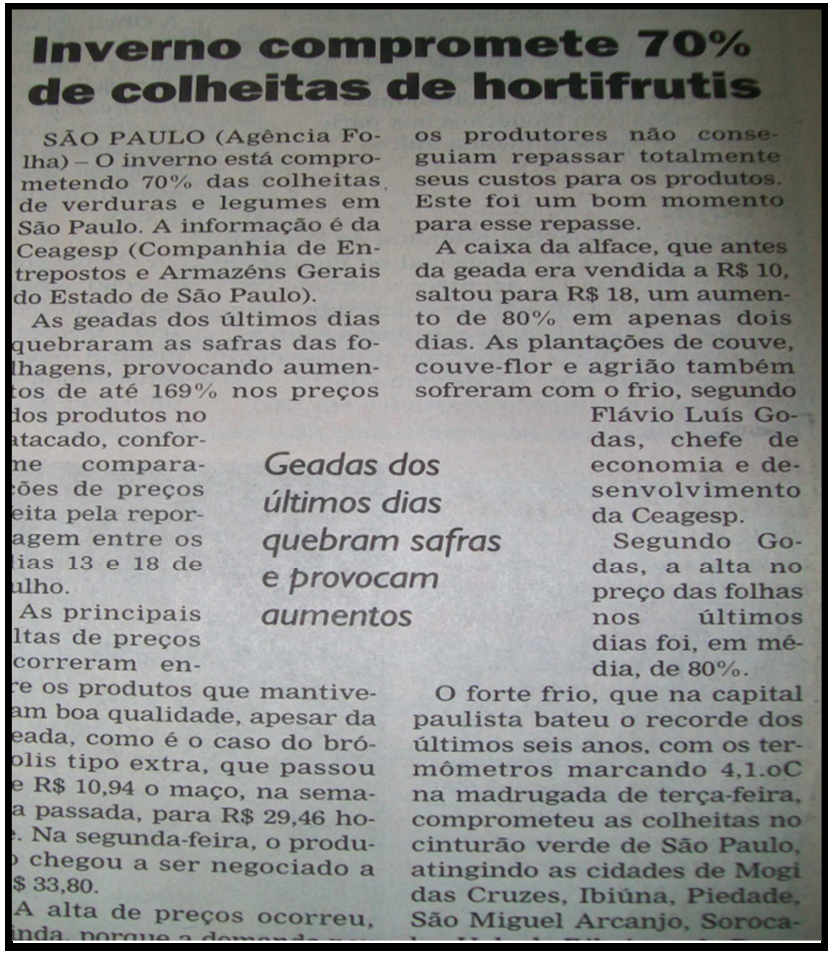

Figura 7 - Notícia publicada pelo "Jornal O Imparcial" Fonte: Jornal O Imparcial (julho de 2000).

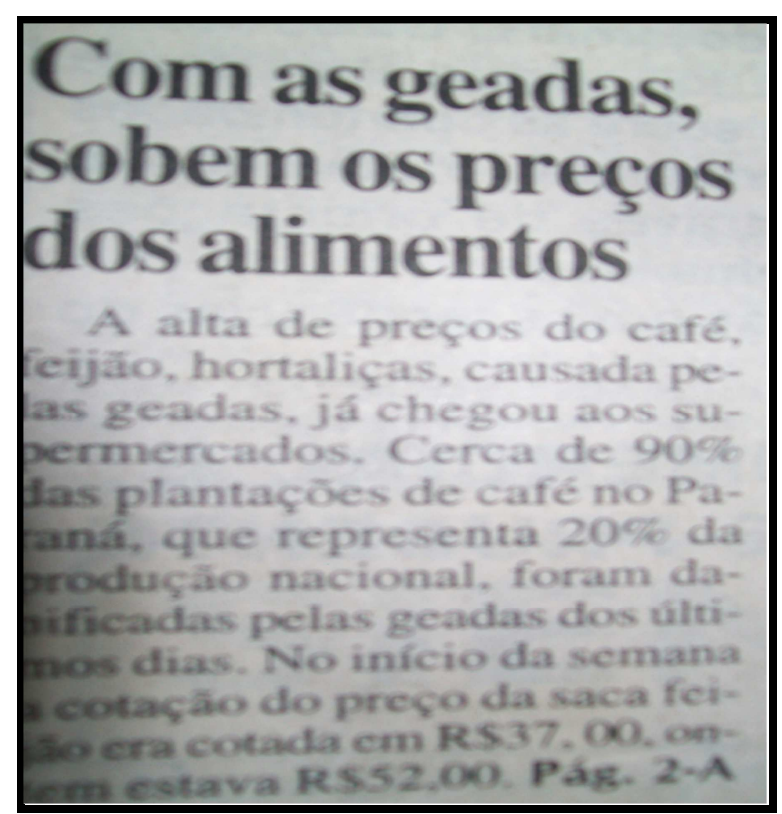

Figura 8 - Notícia publicada pelo "Jornal Oeste Notícias" Fonte: Jornal Oeste Notícias (julho de 2000). 


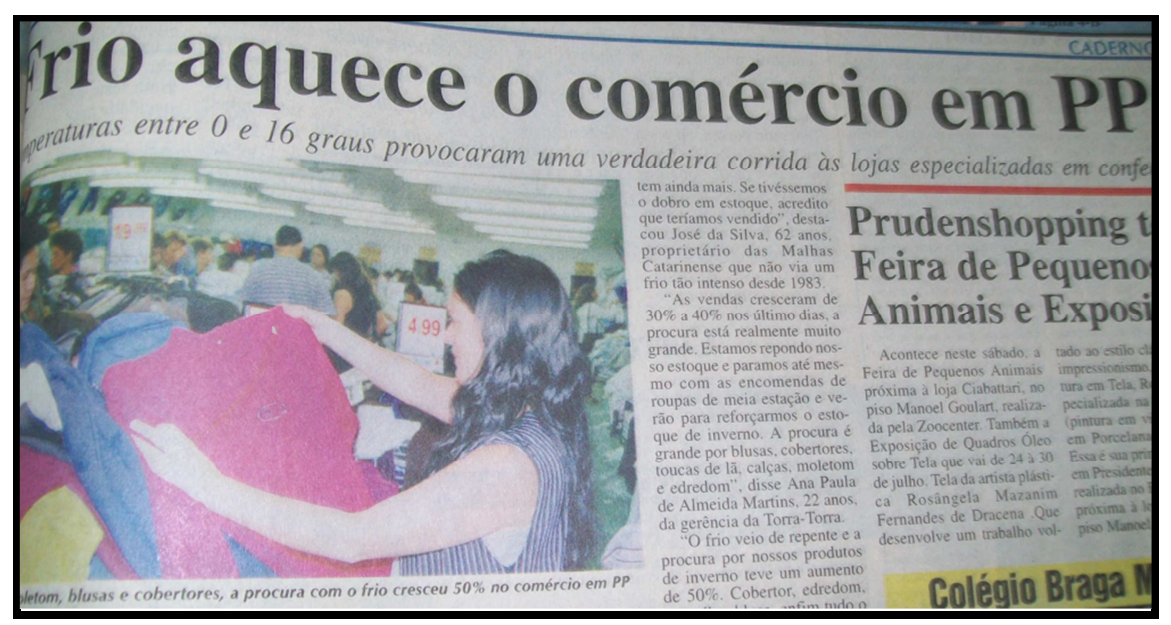

Figura 9 - Notícia publicada pelo "Jornal Oeste Notícias" Fonte: Jornal Oeste Notícias (julho de 2000).

Ao longo do mês de julho, pode-se observar uma grande quantidade de notícias referente aos fenômenos climáticos que afligiram os prudentinos e, dessa forma, revelam a grande repercussão desses fenômenos no espaço geográfico.

Com a realização de algumas perguntas feitas às pessoas que trabalham na área da saúde na cidade de Presidente Prudente, pode-se confirmar o aumento de consultas nos hospitais e postos de saúde da cidade, onde na maioria dos casos as enfermidades que se fazem mais presentes nesta época do ano em questão (inverno), são as do aparelho respiratório, tais como gripes, resfriados, dores de ouvido (otites), dores de gargantas (amigdalite), agravamentos de sinusite, rinite, asma, bronquites, entre outras. Os tipos de remédios mais receitados são aqueles que amenizam os diversos sintomas causados pelas doenças do aparelho respiratório, tais como antitérmicos, antialérgicos, antigripais, antibióticos, suplementos vitamínicos, entre outros.

Assim, com a diminuição das temperaturas durante certo período de tempo, há o agravamento de doenças do aparelho respiratório, em especial em pessoas com mais predisposição as mesmas, aos grupos de risco (crianças e idosos, por permanecerem mais tempo em casa) e as pessoas de menor poder aquisitivo, por residirem em locais inadequados, ou até mesmo, que não oferecem nenhum tipo de conforto. 


\section{Discussão e Conclusões}

\subsection{Considerações sobre o (des) conforto térmico}

O conforto térmico se baseia em alguns parâmetros fundamentais: temperatura, umidade, radiação solar e direção e velocidade do vento. Esses parâmetros guardam estreitas relações com o regime das chuvas, vegetação, permeabilidade, estruturas térmicas dos imóveis entre outras características locais que são alteradas pela presença humana no espaço geográfico.

O movimento do ar atua nas trocas térmicas por convecção e evaporação, potencializando sua ação. O vento aumenta a dissipação de energia, acelerando a evaporação por convecção e atua ainda como dispersor de energia. Em baixas temperaturas a sensação de desconforto pode aumentar e em temperaturas superiores a $40^{\circ} \mathrm{C}$ aumentar a sensação de calor.

Já a temperatura, sendo um dos principais elementos para a representação do conforto ou desconforto térmico, pode variar em diversas situações sendo associadas a outros elementos climáticos. Com situações de mesma temperatura as sensações térmicas podem variar em relação à quantidade de umidade do ar, velocidade do vento e da quantidade de radiação solar recebida.

Como afirma Ikefuti (2009) a umidade em locais de altas temperaturas assume um papel importante, pois regula a evaporação, controlando assim, a quantidade de transpiração sofrida. A zona de umidade relativa considerada agradável para o ser humano está compreendida entre $40 \%$ e $60 \%$ entre as temperaturas de $23,9^{\circ} \mathrm{C}$ e $25,6^{\circ} \mathrm{C}$ (Olgyay, 1998 ). Acima disto as perdas por evaporação são dificultadas pela grande quantidade de vapor d'água já contida no ambiente, e abaixo disto é grande o risco de contaminações em decorrência do ar seco.

O ser humano sendo um animal homeotérmico, onde seu organismo é mantido sempre a uma temperatura interna sensivelmente constante, sendo essa em torno de $37^{\circ} \mathrm{C}$, com limites estreitos - entre 36,1 e $37,2^{\circ} \mathrm{C}$. O organismo humano experimenta sensação de conforto térmico quando perde para o ambiente, sem recorrer a nenhum mecanismo de termorregulação, o calor produzido pelo metabolismo compatível com sua atividade exercida. 
Assim o ser humano demostra através de reações ao frio e ao calor, algumas características que valem ser explicitadas. Quando as condições ambientais proporcionam perdas de calor do corpo além das necessárias para a manutenção de sua temperatura interna constante, o organismo reage por meio de seus mecanismos automáticos (sistema nervoso simpático), buscando reduzir as perdas e aumentar as combustões internas. Sendo percebidas através da pele por meio da vasoconstrição, do arrepio, do tiritar. (Frota e Schiffer, 2003, p. 20).

O canal da percepção do conforto térmico (Subsistema Termodinâmico do sistema Clima Urbano proposto por Monteiro, 1976) está ligado às variáveis de temperatura e umidade, que não podem ser desvinculadas dos demais elementos climatológicos, pois a temperatura que é alterada pela cidade gera uma ventilação urbana, que interfere na condensação e precipitação, ou seja, todos os elementos se inter-relacionam e interferem no comportamento dos demais dentro do sistema.

Sendo assim se faz necessário conhecer os elementos climáticos que interferem no conforto ou desconforto térmico gerado nas pessoas, levando em consideração a infraestrutura dos imóveis (matérias de construção, cor, luminosidade, radiação solar recebida, direção dos ventos, entre outros), a aclimatização das pessoas ao lugar onde vivem, a organização do espaço urbano, em que, na maioria das vezes, temos moradias muitos próximas uma das outras, além da especulação imobiliária em detrimento da qualidade de vida urbana e conforto térmico para as pessoas que ali habitam.

\subsection{Algumas mitigações para os episódios de onda de frio}

É indiscutível a importância do planejamento urbano para propiciar condições de conforto térmico para a sociedade como um todo. Obviamente que o processo de uso e ocupação do solo pelos mais diversos agentes sociais influencia diretamente nessa relação. Dessa forma, a espacialização de um evento extremo em uma determinada região ocasiona efeitos distintos nas mais diversas localidades.

A lógica da ocupação urbana no atual sistema socioeconômico determina as consequências diretas dos eventos extremos para a população das cidades. Nas localidades onde os materiais construtivos são inadequados o conforto térmico é dificultado (ou mesmo inexistente), ou seja, as diferenças de materiais (e do próprio entorno: vegetação, 
edificações etc.) são responsáveis pela ocorrência das diversas temperaturas em uma mesma região (Ikefuti, 2009).

Os materiais construtivos, típicos de moradias dos bairros de baixo poder aquisitivo no interior paulista, em especial na cidade de Presidente Prudente, caracterizam-se por apresentarem desconforto térmico, tanto pelo armazenamento excessivo de calor, no verão, quanto por não protegerem a entrada de ar frio, no inverno. Isso se deve pela pequena espessura das paredes, que causam a falta de isolamento térmico em seu interior, e, também, pela ausência de forro ou laje, associada à utilização de cobertura com telhas de cimento amianto (Souza, 2007).

Para pensarmos numa construção eficiente do ponto de vista térmico devemos, em primeiro lugar, prestar atenção na possibilidade de utilizar o aquecimento passivo. Isso nada mais é do que aproveitar a radiação solar para esquentar a nossa casa e, uma vez que o calor esteja lá dentro, tentar segurá-lo o máximo de tempo possível. Nesse sentido é importantíssimo prestarmos atenção para alguns fatores como, implantação (tamanho do terreno, espaço entre o muro, etc), orientação e tamanho das aberturas (verificando a orientação do sol, a direção dos ventos e predominância da direção dos mesmos na cidade), os caixilhos (ao comprar caixilhos e esquadrias, não leve apenas o preço em consideração; observe o acabamento, o encaixe entre as peças, certifique-se de que o isolamento é adequado), proteção dos ventos (verifique a orientação dos ventos e posicione corretamente as aberturas do imóvel) e a massa térmica (o corpo) da construção (quanto maior a massa térmica de uma construção, mais isolante ela será), sendo essas algumas medidas que podem ser tomadas para amenizar os efeitos das ondas de frio, mas não podendo esquecer que a grande parte dos dias do ano na cidade é de temperaturas mais elevadas, assim propõe-se algumas medidas para aqueles meses com temperaturas mais baixas, visando a amenização das mesmas.

\subsection{Conclusões sobre o episódio de frio}

O episódio datado de julho de 2000 na cidade de Presidente Prudente trouxe perdas para a agricultura e impactos na saúde das pessoas. Constatamos temperaturas mínimas absolutas de $2,2^{\circ} \mathrm{C}$ em uma cidade que apresenta temperaturas elevadas em boa parte do ano. $\mathrm{A}$ 
permanência de temperaturas baixas para o padrão da cidade, resulturam num episódio de onda de frio, ocasionando certo desconforto na população da cidade.

Ressalta-se também uma análise temporal e dos efeitos em escala regional (como La Niña e outros fatores que interferem na itensidade da entrada de frentes frias e consequetemente ar polar no Brasil) mais detalhada. Porém, a análise diária do evento de onda de frio (dados meteorológicos de superfície, análise dos sistemas atmoféricos e das notícias difundidas pela mídia local) e das temperaturas médias mínimas e máximas (entre 1961 a 2010) em Presidente Prudente demostraram resultados interessantes para o presente trabalho.

Deste modo, é necessário incorporar a dimensão social na interpretação do clima urbano, isto é, compreender que a repercussão dos fenômenos atmosféricos na superfície se dá de maneira desigual. Em outras palavras, a entrada de um sistema atmosférico, como uma frente fria, se espacializa de maneira mais ou menos uniforme num determinado espaço, em escala local. Entretanto, em termos socioeconômicos, este sistema produzirá diferentes efeitos em função da capacidade (ou possibilidade) que os diversos grupos sociais têm para se defender.

\section{Referências}

Amorim, M. C. C. T. O clima urbano de Presidente Prudente/SP. São Paulo, 2000. Doutoramento, Faculdade de Filosofia, Letras e Ciências Humanas, Universidade de São Paulo.

Brasil, Instituto Brasileiro de Geografia e Estatistíca (2010). Censo Demográfico 2010. Rio de Janeiro.

Brasil, Marinha do Brasil (2000). Cartas sinóticas de superfície. Brasil.

Boin, M. N. Chuvas e erosões no Oeste Paulista: uma análise climatológica aplicada. Rio Claro, 2000. 264.p. Doutoramento, IGCE/UNESP - Rio Claro.

Estação meteorológica da Faculdade DE Ciências E Tecnologia de Presidente Prudente, UNESP. Base de medições dos elementos meteorológicos: 1969/2010. Faculdade de Ciências e Tecnologia, Universidade Estadual Paulista, Presidente Prudente, 2011.

Frota, A. B. E Schiffer, S. R. Manual do Conforto Térmico. 8a ed. São Paulo: Studio Nobel, 2003.

Firpo, M. A. F.; Sansigolo, C. A.; Assis, S. V. de. Climatologia e variabilidade sazonal do número de ondas de calor e de frio no Rio Grande do Sul associadas ao enos. Revista Brasileira de Meteorologia, v.27, n.1, 95-106, 2012.

Guiar, A. A. de. o que esperar do clima no inverno? Disponível em: http://www.metsul.com/secoes/visualiza.php?cod_subsecao=47\&cod_texto=796 METSUL Meteorologia, 2007.

Ikefuti, P. V. Estudos do conforto térmico em Bairros com diferentes padrões de Construções em presidente prudente. Presidente Prudente, 2009. Monografia de Bacharelado em Geografia, Faculdade de Ciências e Tecnologia, Universidade Estadual Paulista. 
Jornal “O Imparcial”, Julho de 2000, Presidente Prudente, 2011.

Jornal “Oeste Notícias”, Julho de 2000, Presidente Prudente, 2011.

Monteiro, A. Riscos climáticos: hazards, áleas, episódios extremos. Climatologia urbana e regional. Questões teóricas e estudos de casos. Amorim, M. C. C. T.; Sant'Anna Neto, J. L.; Monteiro, A. São Paulo, Outras expressões, p. 143-172, 2013.

Monteiro, C. A. F. Clima Urbano. Teoria e clima urbano. Clima urbano, Mendonça, F. E Monteiro, C. A. F. São Paulo, Contexto, p. 09-18, 2003.

Monteiro, C. A. de F. Análise rítmica em climatologia. Climatologia, n. 1, São Paulo, Igeog/USP, 1971.

Olgyay, V. Arquitetura y clima: manual de diseño bioclimatico para arquitectos y urbanistas. Barcelona, Gustavo Gilli, 1998.

Sant'anna Neto, J. L. E Tommaselli, J. T. G. O Tempo e o Clima de Presidente Prudente. FCT-UNESP, Presidente Prudente, 2009.

Souza, C. G. de. A influência do ritmo climático na morbidade respiratória em ambientes urbanos. Presidente Prudente, 2009. Dissertação de Mestrado, Faculdade de Ciências e Tecnologia, Universidade Estadual Paulista.

Souza, C. G. de. Análise dos episódios climáticos extremos no Oeste Paulista a partir das notícias veiculadas pela imprensa local. Presidente Prudente, 2005. Monografia de Bacharelado em Geografia, Faculdade de Ciências e Tecnologia, Universidade Estadual Paulista. 